\title{
Quantification of healthy follicles in the neonatal and adult mouse ovary: evidence for maintenance of primordial follicle supply
}

\author{
J B Kerr, R Duckett ${ }^{1}$, M Myers, K L Britt ${ }^{2}$, T Mladenovska and J K Findlay ${ }^{2}$ \\ Department of Anatomy and Cell Biology, Faculty of Medicine, Nursing \& Health Sciences, School of Biomedical \\ Sciences, Building 13C, Monash University, Clayton, Victoria 3800, Australia, ${ }^{1}$ School of Human Biosciences, \\ LaTrobe University, Bundoora, Victoria, Australia and 'Prince Henry's Institute of Medical Research, Clayton, \\ Victoria, Australia \\ Correspondence should be addressed to J Kerr; Email: jeff.kerr@med.monash.edu.au
}

M Myers is now at Obstetrics and Gynaecology, The Queen's Medical Research Institute, Centre for Reproductive Biology, University of Edinburgh, Scotland, UK

K L Britt is now at Breakthrough Breast Cancer Centre, The Institute of Cancer Research, Chester Beatty Laboratories, Fulham Road, London, UK

\begin{abstract}
Proliferation and partial meiotic maturation of germ cells in fetal ovaries is believed to establish a finite, non-renewable pool of primordial follicles at birth. The supply of primordial follicles in postnatal life should be depleted during folliculogenesis, either undergoing atresia or surviving to ovulation. Recent studies of mouse ovaries propose that intra- and extraovarian germline stem cells replenish oocytes and form new primordial follicles. We quantified all healthy follicles in C57BL/6 mouse ovaries from day 1 to 200 using unbiased stereological methods, immunolabelling of oocyte meiosis (germ cell nuclear antigen (GCNA)) and ovarian cell proliferation (proliferating cell nuclear antigen (PCNA)) and electronmicroscopy. Day 1 ovaries contained $7924 \pm 1564$ (s.E.M.) oocytes or primordial follicles, declining on day 7 to $1987 \pm 203$, with 200-800 oocytes ejected from individual ovaries on that day and day 12. Discarded oocytes and those subjacent to the surface epithelium were GCNA-positive indicating their incomplete meiotic maturation. From day 7 to 100 mean numbers of primordial follicles per ovary were not significantly depleted but declined at 200 days to $254 \pm 71$. Mean numbers of all healthy follicles per ovary were not significantly different from day 7 to 100 (range $2332 \pm 349-3007 \pm 322$ ). Primordial follicle oocytes were PCNA-negative. Occasional unidentified cells were PCNA-positive with mitotic figures observed in the cortex of day 1 and 12 ovaries. Although we found no evidence for ovarian germline stem cells, our data support the hypothesis of postnatal follicle renewal in postnatal and adult ovaries of $\mathrm{C} 57 \mathrm{BL} / 6 \mathrm{mice}$.
\end{abstract}

Reproduction (2006) 132 95-109

\section{Introduction}

It is a widely held view that the mammalian neonatal ovary contains a finite stockpile of non-growing primordial follicles each of which encloses an oocyte arrested at the diplotene step of meiotic prophase (reviewed by Zuckerman 1951, Peters 1969, Albertini 2004, Gosden 2004, Telfer 2004, Greenfeld \& Flaws 2004, Telfer et al. 2005). Commencing at or soon after birth, small numbers of primordial follicles become activated each day and enter a folliculogenic growth phase during which follicles either degenerate by atresia or, depending on the species, one or more complete their maturation resulting in ovulation. During adult life, the supply of follicles is said to decline until advancing age, when the primordial pool is exhausted (Gosden et al. 1983, Richardson et al. 1987).

The notion of a fixed, non-renewable reserve of primordial follicles has been questioned by several earlier studies of primate species, where in adult ovaries mitotically active germ cells in nests or single oogonia have been reported (Vermande-van Eck 1956, Duke 1967, Ioannou 1967, Butler \& Juma 1970, Anand Kumar 1974, David et al. 1974). Adult ovaries of Drosophila contain germline stem cells that renew oocyte supply (Lin \& Spradling 1995, Deng \& Lin 2001, Spradling et al. 2001, Wang \& Lin 2004). In adult human ovaries, surface epithelial cells derived from the tunica albuginea, are reported to differentiate into granulosa cells and oocytes forming new follicles (Bukovsky et al. 1995, 
2004, Bukovsky 2005). Mitotically active cells in the ovarian surface epithelium (OSE) of juvenile and adult mice were suggested by Johnson et al. (2004) to be a source of germline stem cells capable of regenerating the population of primordial follicles. Studies by Tan \& Fleming (2004) on the OSE in mice found no evidence for mitotic germ cells and a low incidence of PCNA immunoreactivity among OSE cells distant from ovulation rupture sites. The concept of OSE cells as the source of germline cells was subsequently revoked by Johnson et al. (2005a) in favour of bone marrow and peripheral blood cells as the source of new germ cells that infiltrate the ovary to replenish the stock of primordial follicles.

The existence of ovarian germline stem cells suggested by Johnson et al. (2005a) in part was based upon their observation that in response to experimental depletion of primordial follicles, newly formed oocyte-containing primordial follicles were regenerated within $12 \mathrm{~h}$. A similar de novo proliferation (up to doubling) of primordial follicle numbers in 2- and 34-week-old mouse ovaries was reported $24 \mathrm{~h}$ after trichostatin A treatment (Johnson et al. 2005a), an agent known to expand haemopoietic stem cell populations (Milhem et al. 2004). The initial studies by Johnson et al. (2004) were based upon the quantitative histologic measurements of primordial and total follicle numbers from 4 to 42 days after birth. They reported that the increasing numbers of atretic follicles $(16-33 \%$ of the total follicle population) was suggestive of imminent exhaustion of healthy follicles by early adulthood, which in mice clearly does not occur until 13-14 months of age (Gosden et al. 1983).

To our knowledge, there are no reports of a systematic study of follicle numbers from birth to adulthood in a single strain of mice using unbiased stereological methods. This information is critical to evaluation of claims of germline stem cells in the mouse that can give rise to new primordial follicles. Whilst many studies have assessed follicle numbers in the mouse ovary, the numbers varied significantly according to the stage of folliculogenesis, the methods used, and the strain and age of the mice (reviewed by Myers et al. 2004). Although Faddy et al. (1987) have studied the kinetics of follicle development from birth to day 100 , they used the uncommon $\mathrm{CBA} / \mathrm{Ca}$ strain and their calculations relied upon several unspecified correction factors.

Given the recent evidence for germline stem cells and follicular renewal in the mouse ovary (Johnson et al. 2004, 2005a), we hypothesized that total, and particularly primordial, healthy follicle numbers should remain relatively constant, at least for a significant part of adult reproductive life.

The aim of the present study is to quantify the population of healthy follicles in the neonatal and adult ovaries of C57BL/6 mice, a strain used also in the studies of Johnson et al. (2004, 2005a), using unbiased, assumption-free stereological methods (Gundersen 1986). These techniques have recently been validated in our laboratory (Myers et al. 2004) and by others using C3H wild-type and hpg mice (Wang et al. 2005). In addition, we used immunocytochemistry and ultrastructure to further characterize the healthy follicles in the ovary.

\section{Materials and Methods}

\section{Animals}

Wild-type female C57BL/6 mice were kept on a $12 \mathrm{~h}$ light: $12 \mathrm{~h}$ darkness regimen under specific pathogenfree conditions with mouse chow and water freely available. All animal procedures were approved by the Animal Ethics Committee at Monash University and were carried out in accordance with the 'Australian Code of Practice for the Care and Use of Animals for Scientific Purposes'.

\section{Collection and preparation of tissues}

Both left and right ovaries from each mouse were collected on day $1(n=10), 7(n=6), 12(n=7), 50$ $(n=8), 100(n=7)$ and 200 days $(n=6)$ of age. Female mice were selected from at least four different litters at each time point. Ovaries were randomly assigned to be fixed, either by immersion for 6-12 $\mathrm{h}$ in Bouin's fluid or $4 \mathrm{~h}$ in a mixture of $0.1 \mathrm{M}$ sodium-cacodylate buffered $2.5 \%$ glutaraldehyde, $2 \%$ formaldehyde and $0.1 \%$ picric acid. Bouin's fixed intact ovaries (left or right, one per animal) were processed into hydroxyethyl methacrylate resin (Technovit, 7100, Kulzer and Co., Friedrichsdorf, Germany), serially sectioned at $20 \mu \mathrm{m}$ with a Leica RM2165 microtome (Leica Microsystems Nussloch $\mathrm{GmbH}$, Nussloch, Germany), stained using periodic acid-Schiff and counterstained with haematoxylin for stereological assessment. A total of 2585 sections from 44 ovaries were prepared. For the contralateral ovaries, three per age group were fixed in glutaraldehyde (intact from day 1 to 12 , or cut into 2 to $3 \mathrm{~mm}$ pieces from days 50 to 200), post-fixed for $2 \mathrm{~h}$ in osmium tetroxide, en bloc stained for $1 \mathrm{~h}$ with uranyl acetate and dehydrated, and embedded in an Epon-Araldite mixture. For light microscopy, polymerised blocks were cut at $1 \mu \mathrm{m}$ and stained with toluidine blue. Ultrathin sections were cut with diamond knives, stained with lead citrate and uranyl acetate and examined with a JEOL 1200cx electron microscope. The remaining ovaries, fixed in Bouin's fluid, were processed into paraffin wax and sections cut at $7 \mu \mathrm{m}$ for light microscopy and immunocytochemistry. An additional three ovaries each at 15, 20, 25 and 70 days were fixed in Bouin's fluid and five random sections of each ovary were prepared for immunocytochemistry or histological analysis, but not included in the quantitative assessment. 


\section{Quantification of primordial and primary follicles}

All types of healthy follicles were classified according to the same criteria as detailed in Myers et al. (2004). Estimates of primordial and primary follicle number were made using the Olympus CAST 2 stereological software v2.1.4 (Olympus Denmark A/S, Albertslund, Denmark) on a PC in conjunction with an Olympus BX51 microscope fitted with $\times 100$ oil immersion objective with high numerical aperture $\left(N_{A}=1 \cdot 4\right)$. Microscopic fields were selected using a motorised stage (Autoscan Systems, Brighton, Australia) and systematic uniform random sampling (Gundersen \& Jensen 1987, Wreford 1995). A microcator (D8225, J Heidenhain $\mathrm{GmbH}$, Traunreut, Germany) fitted to the microscope was used to measure the movement of the stage in the z-axis. Oocytes not yet enclosed in primordial follicles in the day 1 ovary and primordial follicles or oocytes in or external to the surface epithelium were also counted.

A fractionator/optical disector design (Gunderson et al. 1988, Wreford 1995) was used to sample tissue in conjunction with an unbiased sampling frame (Gundersen \& Jensen 1987) as described previously (Myers et al. 2004). The number of sections selected from the 2585 making up the serial set (sampling fraction 1 (f1)), the area of the sampling frame and the step length (sampling fraction 2 ( $\mathrm{f} 2)=$ frame $\operatorname{area} /(x$-step $\times y$-step)) was optimized to give the most efficient counting protocol. At each step, the first $3 \mu \mathrm{m}$ was traversed as a guard area against cutting artefacts and then nuclear profiles of primordial and primary follicles were counted in the next $10 \mu \mathrm{m}$ of the $20 \mu \mathrm{m}$ section (sampling fraction $3(\mathfrak{f} 3)=10 / 20$ ) as previously described by Myers et al. (2004). Profiles were counted only if they were inside or partially inside the sampling frame and no part of them touched the exclusion lines of the frame. Raw counts ranged between 80 and 290 for primordial follicles and 15 and 80 for primary follicles. Raw counts $\left(Q^{-}\right)$of follicular numbers were multiplied by the reciprocal of the sampling fractions to estimate the total number $\left(N_{V}\right)$ such that $N_{\mathrm{V}}=Q_{\text {(follicle) }}^{-}(1 / \mathrm{f} 1)(1 / \mathrm{f} 2)(1 / \mathrm{f} 3)$ as previously described (Myers et al. 2004).

\section{Quantification of secondary and antral follicles}

The numbers of more advanced healthy follicles per ovary (secondary and beyond) were estimated by exact counts determined from the digital images of consecutive $20 \mu \mathrm{m}$ hydroxyethyl methacrylate sections encompassing whole cross-sections of ovarian tissue (Myers et al. 2004).

\section{Immunocytochemistry}

For detection of germ cell nuclear antigen (GCNA), a marker of pre-diplotene oocytes of the first meiotic maturation in fetal and early postnatal mouse ovaries (Enders \& May 1994), paraffin sections were dewaxed, hydrated in PBS and a citrate antigen retrieval step was performed $(0.01 \mathrm{M}$ citrate buffer $\mathrm{pH} \mathrm{6,} 10 \mathrm{~min}$ microwave boiling). After cooling, sections were permeabilised with $0.1 \%$ Triton $X$ and incubated for $15 \mathrm{~min}$ in $2 \%$ $\mathrm{H}_{2} \mathrm{O}_{2}$ in methanol to quench endogenous peroxidase. Following blocking for $1 \mathrm{~h}$ with $10 \%$ normal rabbit serum, sections were incubated with primary GCNA antibody (1:200, supplied by Dr George Enders, University of Kansas Medical Centre, Kansas City, KS, USA) for $1 \mathrm{~h}$ at room temperature. Sections were washed in PBS, then incubated with biotinylated secondary antibody (rabbit anti-rat 1:200 in 2\% BSA in PBS) for $1 \mathrm{~h}$. Binding sites were detected by incubation for $1 \mathrm{~h}$ with avidinbiotin-peroxidase, followed by exposure to diaminobenzidine $(D A B)$ reaction for $10 \mathrm{~s}$. Sections were counterstained with haematoxylin, dehydrated and cleared and coverslipped with histomount reagent. Sections of immature/adult mouse testis and small intestine were used as positive and negative controls respectively.

Proliferating cells were detected with a MAB to proliferating cell nuclear antigen (PCNA; Oktay et al. 1995) using a PCNA staining kit (Zymed Laboratories, South San Francisco, CA). As described above, sections were subjected to microwave antigen retrieval, and blocking of endogenous peroxidase and non-specific binding. Sections were incubated with biotinylated mouse anti-PCNA for $38 \mathrm{~min}$ then for $10 \mathrm{~min}$ with streptavidin-peroxidase to bind the primary antibody. Immunostaining was detected with DAB reaction for 2 min followed by haematoxylin counterstaining. Mouse testis and small intestine were used as positive controls, and mouse brain and cardiac muscle were used as negative controls. Sections were dehydrated, cleared and coverslipped with histomount reagent.

\section{Statistical analysis}

Data are presented as means \pm S.E.M. and statistical analysis of follicle number was performed using Sigmastat statistical software v.2 (Jandel Corporation, San Rafael, CA, USA). If data were normally distributed, they were analysed by one-way ANOVA and the significance determined by Tukey's post-hoc test for all pairwise comparisons. The significance was determined by the Kruskal-Wallis test, if the data were not normally distributed and log or reciprocal transformations did not stabilise the variance. Differences were considered significant when $P<0.05$.

\section{Results}

\section{Morphology and immunocytochemistry}

Day 1 ovary

Oocytes of day 1 ovaries occupied both the medullary and cortical regions with oocytes in the former location 
being of larger size (Fig. 1a). At high magnification, some oocytes formed nests with no intervening somatic cells (Fig. 1b), but most oocytes could be classified as primordial follicles based upon their association with squamous-type granulosa cells (Fig. 1c). The ovarian stroma showed blood capillaries, mast cells and pyknotic bodies, the latter identified as compacted, densely staining structures lacking cellular detail. The surface epithelium consisted mostly of a single layer of squamous or cuboidal cells at times attenuated by oocytes lying close to the surface (Fig. 1b-d). Although their identity could not be established, mitotic figures were noted in some cells in day 1 ovaries (Fig. 1e-g), their size, shape and staining features suggested that they were dividing oogonia. The smaller oocytes in cortical locations and associated somatic or granulosa cells showed intense PCNA staining, whereas oocytes in larger follicles in the medulla showed weak or no labelling (Fig. 1h). Some, but not all oocytes in the outer cortex and subjacent to the ovarian surface showed positive labelling for GCNA (Fig. 1i).

\section{Day 7 and day 12 ovaries}

In 7-day ovaries, numerous oocytes were located among the surface epithelial cell layer with the oocyte plasma membrane apparently exposed to the ovarian bursal cavity (Fig. 2a). Other oocytes classified as primordial follicles on the basis of their association with a surrounding layer of squamous-type granulosa cells, were intercalated amongst the squamous cells making up the tunica albuginea or found slightly deeper within the cortex (Fig. 2a). Although oocytes were not labelled with PCNA, within the surface epithelial layer occasional cell nuclei showed positive labelling with PCNA. Their identity could not be determined by morphological criteria (Fig. 2b). Among the population of surface oocytes and those within primordial follicles, many showed positive immunolabelling for GCNA (Fig. 2c).

Whole ovary sections at 12 days showed folliculogenesis up to secondary follicles, and many oocytes or primordial follicles were seen among the cells of the surface epithelium (Fig. 2d). No oocytes in 12-day ovaries were found to be immunopositive for PCNA (Fig. 2e), but occasionally mitotic figures were observed in cells and their size, shape, association with somatic cells and cortical location suggested their identity as proliferating oogonia (Fig. 2f). Numerous oocytes on the surface of the ovary or subjacent to the tunica albuginea were positively labelled with GCNA (Fig. 2g). Examination of semi-thin epoxy sections showed oocytes within the tunica albuginea and others, either single or double oocytes, projecting into the bursal peritoneal cavity (Fig. 2h). At this location, association between such oocytes and surface epithelial cells was lost suggestive of expulsion of oocytes from the ovary (Fig. 2i). Ultrastructural analysis of the ovarian surface confirmed the location of primordial follicles immediately adjacent to the tunica albuginea and superficial to it, between cells of the surface epithelium (Fig. 3a and b). In some views, continuity of the tunica albuginea layer was interrupted by fibroblasts whose orientation suggested a cellular channel linking the surface epithelium directly with the subtunical ovarian cortex (Fig. 3c). Some surface oocytes showed loose association with surface epithelial cells and others were exposed directly to the bursal space lacking enclosure by epithelial cells (Fig. 3d).

\section{Day 14 to day 25 ovaries}

At 14 days, oocytes in primordial follicles or associated with the surface epithelium did not show positive staining for PCNA in contrast to the strong PCNA staining seen in granulosa cells and stromal cells (Fig. 4a). At 15 days, oocytes or primordial follicles were noted in the surface epithelium facing the bursal cavity (Fig. 4b). Primordial follicles in day 25 ovaries also were noted adjacent or superficial to the tunica albuginea (Fig. 4c) and did not show positive staining for PCNA (Fig. 4d). On rare occasions, oocytes associated with the surface epithelium in day 25 ovaries were GCNA-positive (Fig. 4d inset).

\section{Day 50 to day 200 ovaries}

From day 50 and thereafter, primordial follicles were often found close to the ovarian surface (Fig. $5 \mathrm{a}$ and b), but none of their oocytes were stained for PCNA (Fig. 5c) or GCNA (not shown). Occasionally primordial follicles of day 70 ovaries showed twin oocytes or oocytes closely apposed lacking intervening granulosa cells (Fig.5d). Similar double-oocyte or closely apposed primordial follicles were observed in day 100 ovaries (Fig. 5e and f). Primordial follicles in day 200 ovaries were less frequently seen in comparison to younger ages. Oocytes of day 100 or 200 ovaries did not stain with PCNA and double-oocyte follicles were not observed (not shown).

\section{Quantification of the follicle and oocyte population}

A summary of the data obtained is shown in Table 1. Mean primordial follicle numbers and oocytes ( \pm s.E.M.) in day 1 ovaries was $7924 \pm 1564$ and declined significantly $(P<0.001)$ to $1987 \pm 203$ in day 7 ovaries (Table 1 and Fig. 6). There was no significant difference $(P=0.585)$ in the mean numbers of primordial follicles per ovary between day 7 and day 100, the latter containing $2227 \pm 101$ follicles, but at 200 days their mean numbers were significantly reduced $(P=0.002)$ to $254 \pm 71$ (Table 1 and Fig. 6).

Stereological estimates of the mean total numbers of all healthy follicle types per ovary showed no significant difference $(P=0.430)$ between day $7 \quad(2561 \pm 233)$ 

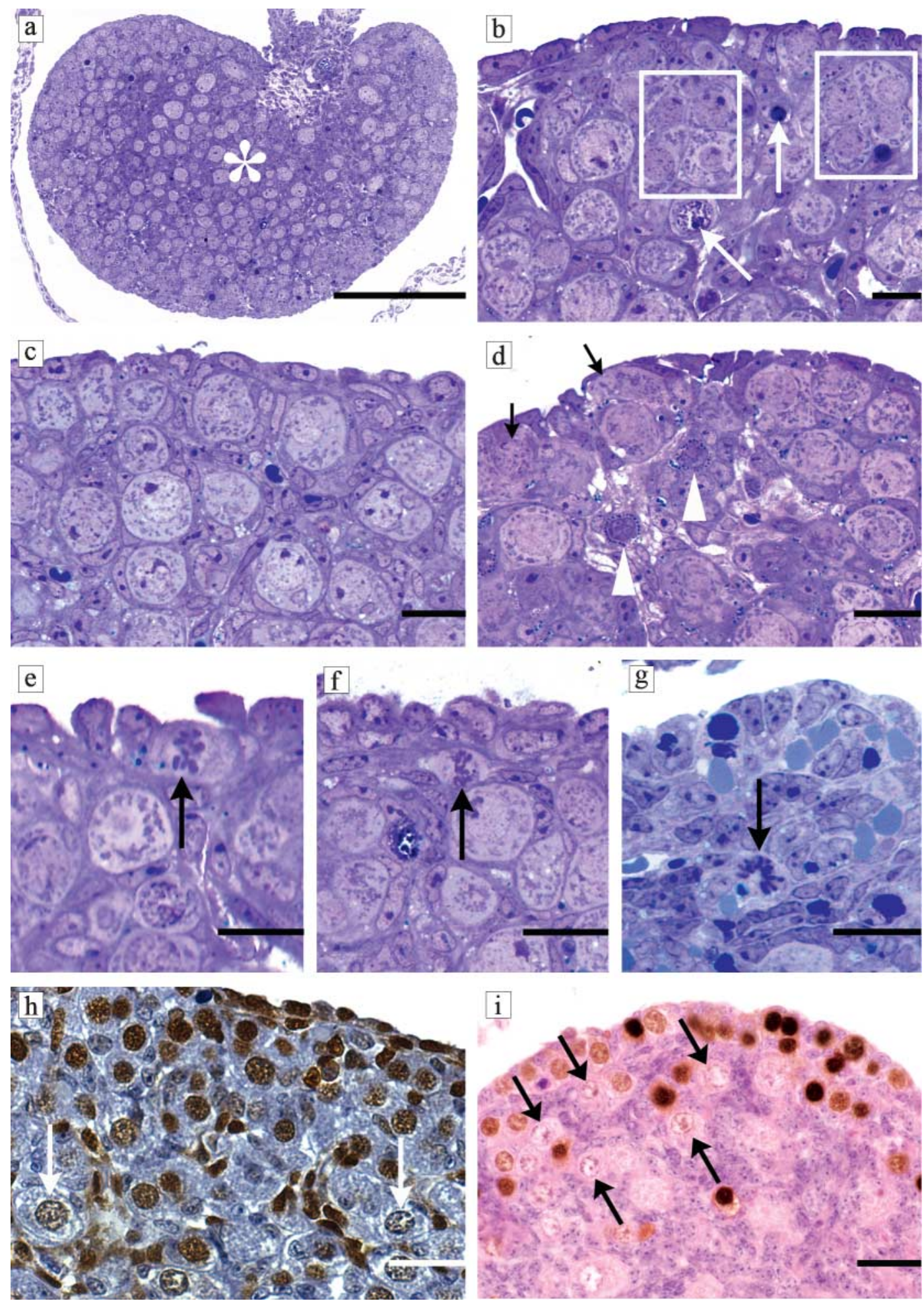

Figure 1 Day 1 ovaries. (a) Whole ovary section showing large oocytes in medulla (asterisk) and smaller compact oocytes in cortical regions. $\mathrm{Bar}=200 \mu \mathrm{m}$. (b) Cortex with nests of oocytes (squares) and pyknotic bodies (arrows). Bar $=15 \mu \mathrm{m}$. (c) Individual primordial follicles associated with early follicle cells. Bar $=15 \mu \mathrm{m}$. (d) Stromal mast cells (arrowheads) and oocytes located very close to the surface of the ovary (arrows). Bar $=15 \mu \mathrm{m}$. (e) Mitotic figure (arrow) at the surface of the ovary. Bar=15 $\mu \mathrm{m}$. (f) Mitotic figure (arrow) deep to tunica albuginea. Bar=15 $\mu \mathrm{m}$. (g) Mitotic figure (arrow) in ovarian cortex. Bar $=15 \mu \mathrm{m}$. (h) Intense PCNA staining of superficial cortical oocytes and weaker stain in oocyte nuclei of deeper primordial follicles (arrows). Bar $=40 \mu \mathrm{m}$. (i) GCNA staining of numerous surface and cortical oocytes with other oocytes showing very weak or no GCNA label (arrows). Bar $=40 \mu \mathrm{m}$. 

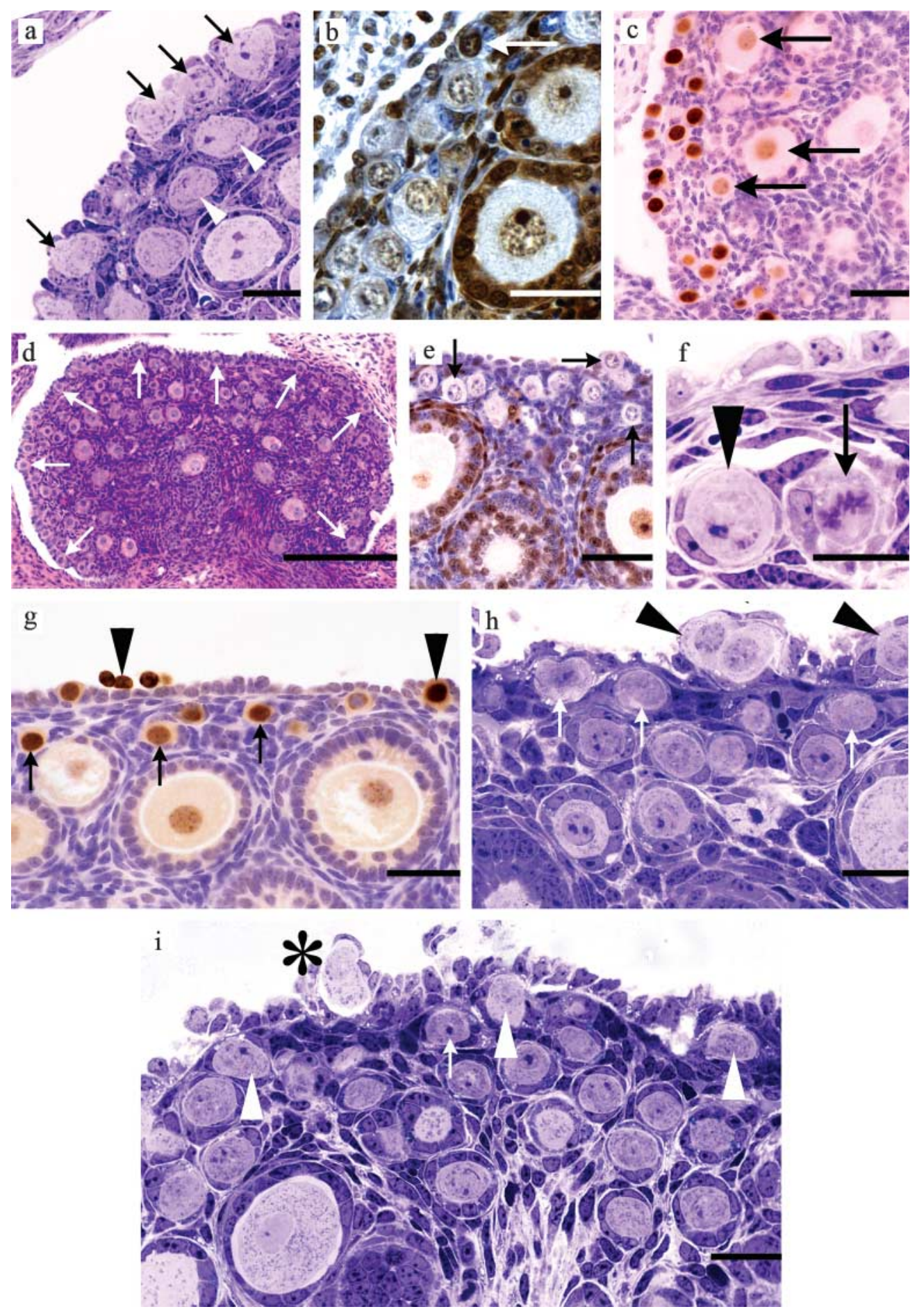

Figure 2 Day 7 (a-c) and day 12 ovaries (d-i). (a) Oocytes (arrows) among surface epithelial cells with primordial follicles also shown (arrowheads). Bar $=20 \mu \mathrm{m}$. (b) PCNA staining of stromal, follicular, and surface epithelial cells; primordial oocyte nuclei are unstained, but note strongly stained nucleus of an unidentified cell (arrow) at ovarian surface. Bar $=30 \mu \mathrm{m}$. (c) GCNA staining of oocyte nuclei at or close to surface epithelium and weak/negative staining of oocytes in deeper primordial and primary follicles (arrows). Bar $=30 \mu \mathrm{m}$. (d) Whole ovary section showing numerous surface oocytes (arrows). Bar $=100 \mu \mathrm{m}$. (e) Lack of PCNA staining of oocytes in primordial follicles and surface oocyte (arrows). Bar $=40 \mu \mathrm{m}$. (f) Primordial follicle (arrowhead) and a mitotic figure (arrow) in the superficial cortex. Bar $=15 \mu \mathrm{m}$. (g) GCNA staining of oocytes on the surface (arrowhead) and in primordial follicles (arrows). Bar $=30 \mu \mathrm{m}$. (h) Oocytes on the surface (arrowheads) and primordial follicles (arrows) in the surface epithelium. Bar $=20 \mu \mathrm{m}$. (i) Oocytes just below (arrow), within (arrowheads) or exiting (asterisk) the surface epithelium. Bar $=20 \mu \mathrm{m}$. 

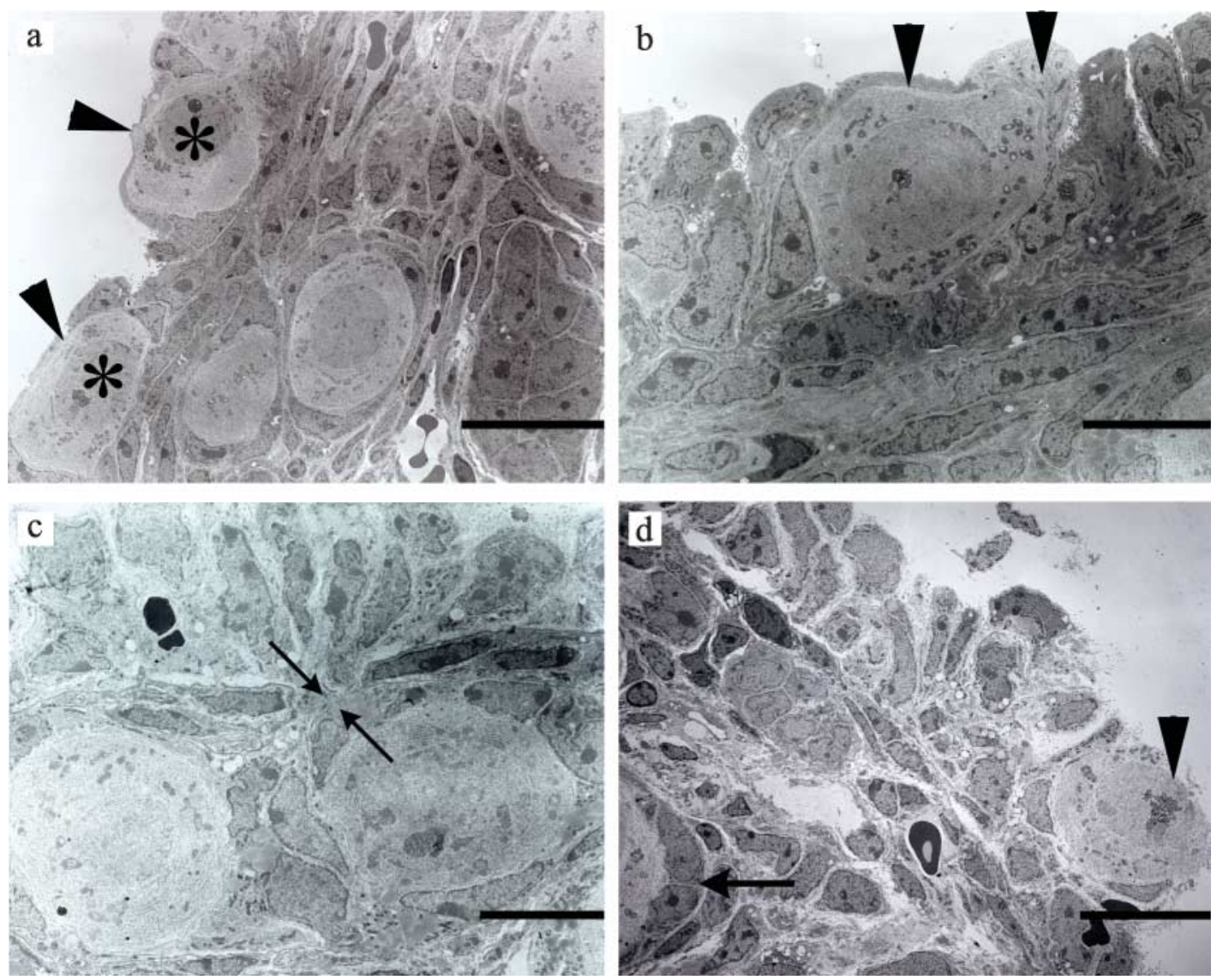

Figure 3 Day 12 ovaries ultrastructure. (a) Two oocytes (asterisks) intercalated in the ovarian surface epithelium (OSE), both covered by attenuated cytoplasm (arrowheads) of surrounding cells. Bar $=10 \mu \mathrm{m}$. (b) Detail of a surface oocyte separated from the periovarian space only by thin processes of surrounding epithelial cells (arrowheads). Bar $=10 \mu \mathrm{m}$. (c) Oocytes of primordial follicles deep to the tunica albuginea showing a discontinuity (arrows) into which surface epithelial cells are inserted. Bar $=10 \mu \mathrm{m}$. (d) Exiting oocyte associated with the surface epithelium showing disintegration of the oocyte cytoplasm (arrowhead) facing the periovarian space. Part of a primary follicle is shown (arrow). Bar $=10 \mu \mathrm{m}$.

and day $100(2607 \pm 115)$, but a significant decline $(P<0.005)$ at day 200 with $425 \pm 86$ follicles per ovary (Table 1 and Fig. 7). The mean numbers of follicle types per ovary from day 7 to 200 are shown in Table 1 and Fig. 8. The mean numbers of primary follicles per ovary from day 7 to 100 ranged between $569 \pm 35$ (day 7) and $243 \pm 28$ (day 100), and comprised $9-21 \%$ of the total follicle population. In day 200 ovaries, mean primary follicle number was $106 \pm 18$ comprising $25 \%$ of total follicle numbers due to the overall reduction in follicle numbers at that age. Secondary and antral follicle numbers per ovary were very small at day 7 (only $5 \pm 4$ secondary follicles) and somewhat variable between day 12 and 200 comprising $4-15 \%$ of total follicle numbers per ovary (Table 1 and Fig. 8).

\section{Discussion}

This study has demonstrated that following a marked depletion of follicles and oocytes during the first postnatal week, mean primordial follicle numbers per ovary did not decline significantly in the subsequent
13 weeks up to day 100 of age in the C57BL/6 strain of mice. The persistence of follicle numbers in the primordial follicle pool from day 7 to 100 and their recruitment into the population of growing follicles was accompanied by no significant decay in the total numbers of all healthy follicles over the same time period.

Our data for follicle numbers per ovary was obtained using unbiased stereological methods that have been validated in the mouse (Sonne-Hansen et al. 2003, Myers et al. 2004, Wang et al. 2005) and in the primate ovary (Miller et al. 1997). Quantitative estimates obtained here are number-weighted rather than volume-weighted, and are independent of ovarian volumes and of follicle size, shape and distribution, and do not rely upon correction factors based on assumptions associated with these parameters or section thickness. In quantifying follicle types in the postnatal and adult ovary, we were interested in studying follicle supply and maturation versus age and, therefore, confined our assessment to morphologically healthy follicles. Critical to these findings is the difficulty 

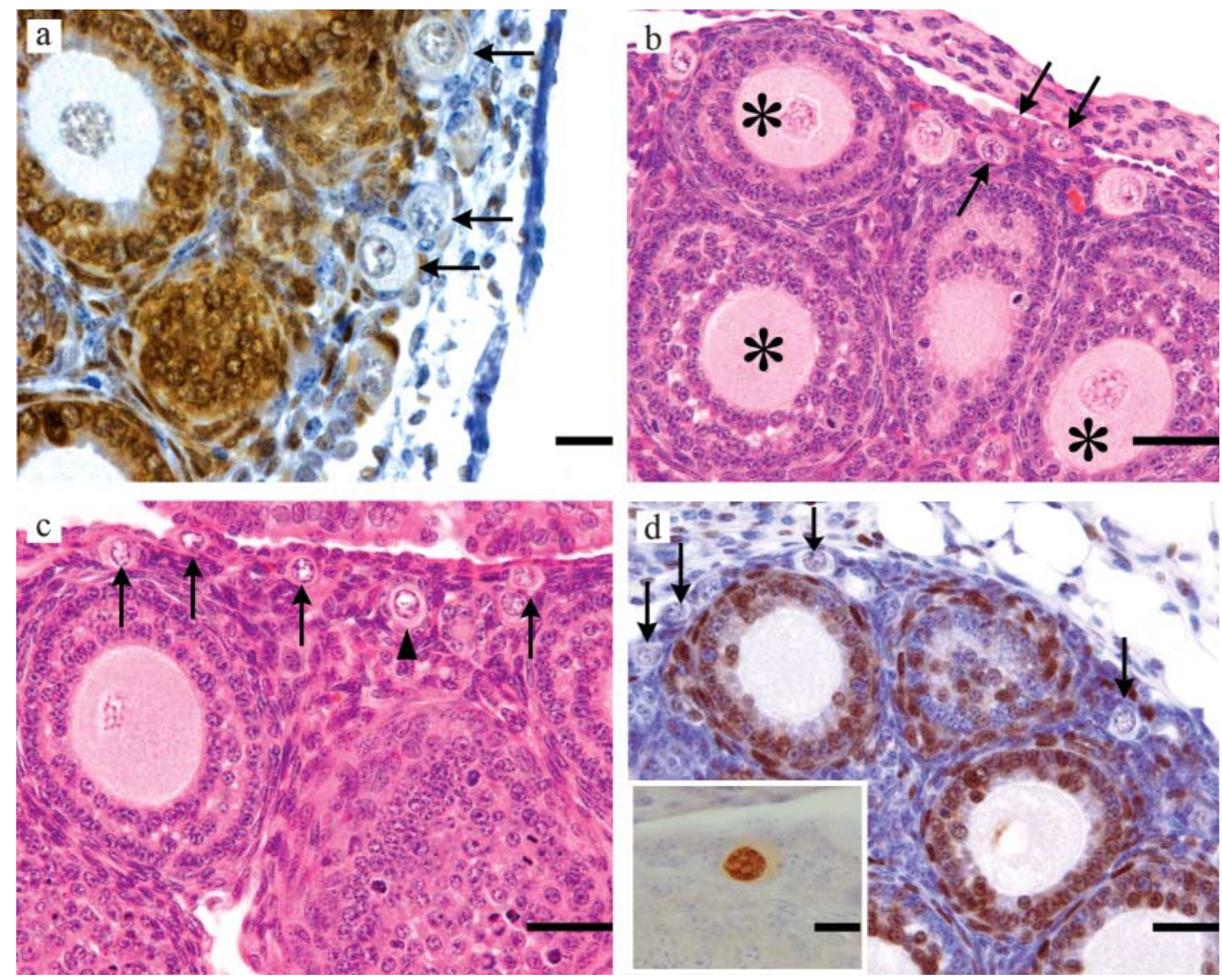

Figure 4 (a) Day 14 ovary after PCNA staining. Oocytes of primordial follicles (arrows) are unstained, whereas surface epithelial cells, stromal and follicular cells showing strong staining. Bar $=15 \mu \mathrm{m}$. (b) Day 15 ovary showing primordial follicles (arrows) adjacent to and on the ovarian surface. Larger preantral follicles (asterisks) are indicated. Bar $=30 \mu \mathrm{m}$. (c) Day 25 ovary showing primordial follicles adjacent to or within the surface epithelium (arrows). A primary follicle is indicated (arrowhead). Bar $=30 \mu \mathrm{m}$. (d) Day 25 ovary after PCNA staining. Oocytes of primordial follicles (arrows) are unstained. Bar $=30 \mu \mathrm{m}$. Inset: GCNA labelling of an oocyte in the surface epithelium of a day 25 ovary. Bar $=15 \mu \mathrm{m}$.

of quantifying folliculogenesis by attempting to identify both healthy and atretic follicles, the reliability of methods used for identifying the morphological criteria of degeneration among primordial/early preantral follicles, and the accuracy of counting these structures in paraffin sections. Histological examples of atretic primordial follicles in postnatal or adult ovaries are very limited (Perez et al. 1999, Depalo et al. 2003). The uncertainties associated with purely morphologic characteristics used to classify cell death among follicles and the unreliability of healthy vs atretic follicle quantification using non-stereological methods has been established (Tilly 2003, Myers et al. 2004). Interpretation of the patterns of follicle growth based upon morphological criteria is dependent on at least two variables: strain differences in folliculogenesis, and the methods used to quantify follicle types. We have previously shown that strain differences also account for major variations in the assessment of ovarian histology with regard to the types and numbers of the follicles (Myers et al. 2004). The present study is the first to apply unbiased stereological techniques for the quantification of healthy follicles in the developing ovary of a single strain, C57BL/6.

Our estimate of the mean number of healthy primordial follicles and oocytes in the day 1 ovary was $7924 \pm 1564$. In newborn ovaries of the NMRI strain, Sonne-Hansen et al. (2003) reported a total of $6812 \pm 1900$ oocytes (mean \pm s.D.) using optical disector stereological methods. From counts made using paraffin sections and applying correction factors to the data, McClellan et al. (2003) found a total of $7688 \pm 350$ GCNA-positive oocytes in 2-day-old ovaries of the CD-1 strain, and in day 1 ovaries of C57BL/ 6 mice, Johnson et al. (2004) reported a mean value of $8338 \pm 1150$ nonatretic oocytes.

Beginning with an endowment of approximately 8000 oocytes (in nests or within primordial follicles) on day 1 , total follicle number per ovary declined $60 \%$ to $2561 \pm 233$ by day 7 . Depletion of primordial follicles in the postnatal mouse ovary is well documented. In addition to recruitment into the growth phase, their diminishing number is in part attributable to oocyte apoptosis (Franchi \& Mandl 1962, Peters 1969, 

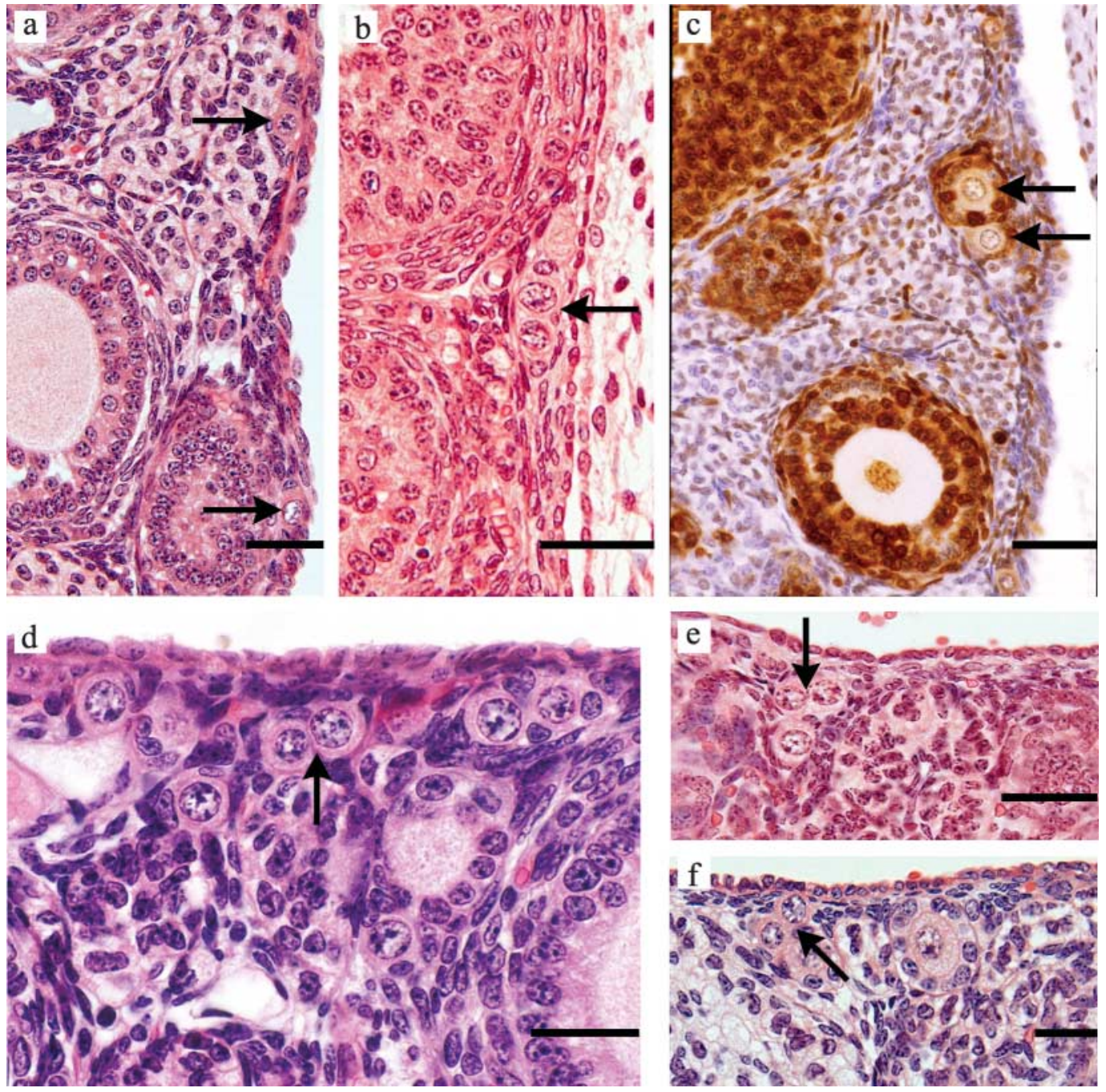

Figure 5 (a) Day 50 ovary showing primordial follicles (arrows) close to or within the surface epithelium. Bar $=30 \mu \mathrm{m}$. (b) Day 50 ovary showing double-oocyte or closely apposed primordial follicles (arrow). Bar $=30 \mu \mathrm{m}$. (c) Day 50 ovary after PCNA staining. Oocyte nuclei are unstained (arrows) and follicular cells are heavily stained (arrowheads). Bar $=30 \mu \mathrm{m}$. (d) Day 70 ovary showing closely apposed oocytes of primordial follicles (arrow). Bar $=30 \mu \mathrm{m}$. (e,f) Day 100 ovaries showing closely apposed oocytes of primordial follicles (arrows). Bars $=30 \mu \mathrm{m}$.

Byskov \& Rasmussen 1973, Morita \& Tilly 1999, Morita et al. 1999, Perez et al. 1999) and also to follicle atresia (Jones \& Krohn 1961a,b, Faddy et al. 1987, Ratts et al. 1995, Pepling \& Spradling 2001, Johnson et al. 2004). A further mechanism that reduces oocyte and follicle numbers in the mouse is by expulsion from the ovary (Jones \& Krohn 1961a, Peters 1969, Hiura \& Fujita 1977, Wordinger et al. 1990). In the first 2 weeks after birth

Table 1 Numbers of follicles and oocytes in postnatal mouse ovaries.

\begin{tabular}{|c|c|c|c|c|c|c|c|c|}
\hline Age in days $(n)$ & $\begin{array}{l}\text { Primordial } \\
\text { follicles (1) }\end{array}$ & $\begin{array}{l}\text { Primordial }+ \\
\text { intratunical } \\
\text { primordial } \\
\text { follicles }(2)\end{array}$ & $\begin{array}{l}\text { Ejected } \\
\text { oocytes }\end{array}$ & $\begin{array}{l}\text { Primary } \\
\text { follicles }\end{array}$ & $\begin{array}{l}\text { Secondary } \\
\text { follicles }\end{array}$ & $\begin{array}{l}\text { Antral } \\
\text { follicles }\end{array}$ & $\begin{array}{l}\text { Total follicles } \\
\text { with column } \\
(1)\end{array}$ & $\begin{array}{l}\text { Total follicles- } \\
\text { with column } \\
(2)\end{array}$ \\
\hline $1(10)$ & $7924 \pm 1564$ & $\rightarrow$ same & $\mathrm{Nil}$ & $\mathrm{Nil}$ & $\mathrm{Nil}$ & $\mathrm{Nil}$ & $7924 \pm 1564$ & $7924 \pm 1564$ \\
\hline $7(6)$ & $1688 \pm 154$ & $1987 \pm 203$ & $460 \pm 59$ & $569 \pm 35$ & $5 \pm 4$ & $\mathrm{Nil}$ & $2262 \pm 188$ & $2561 \pm 233$ \\
\hline $12(7)$ & $2107 \pm 272$ & $2317 \pm 289$ & $561 \pm 85$ & $362 \pm 34$ & $328 \pm 34$ & Nil & $2797 \pm 306$ & $3007 \pm 322$ \\
\hline $50(8)$ & $1976 \pm 306$ & $\rightarrow$ Same & $\mathrm{Nil}^{-}$ & $259 \pm 39$ & $70 \pm 19$ & $27 \pm 5$ & $2332 \pm 349$ & $\rightarrow$ Same \\
\hline $100(7)$ & $2227 \pm 101$ & $\rightarrow$ Same & $\mathrm{Nil}$ & $243 \pm 28$ & $79 \pm 5$ & $58 \pm 7$ & $2607 \pm 115$ & $\rightarrow$ Same \\
\hline $200(6)$ & $254 \pm 71$ & $\rightarrow$ Same & $\mathrm{Nil}$ & $106 \pm 18$ & $46 \pm 4$ & $20 \pm 3$ & $425 \pm 86$ & $\rightarrow$ Same \\
\hline
\end{tabular}

Data represent mean \pm S.E.M. Entries $\rightarrow$ same indicate data identical to that in column immediately to the left. 


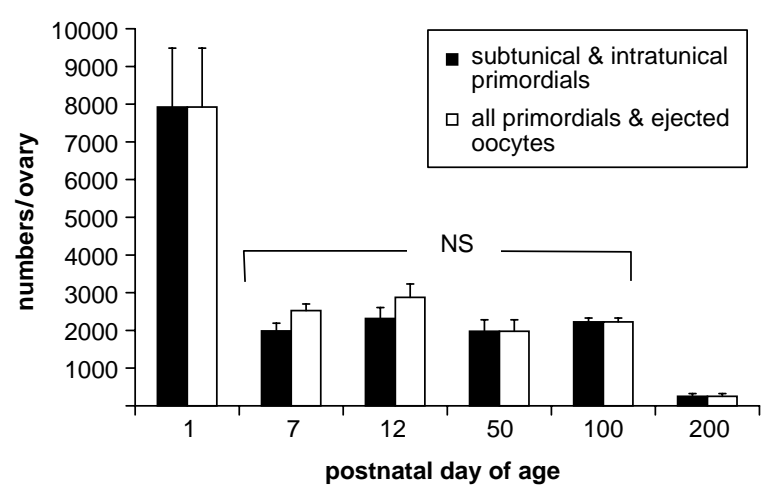

Figure 6 Oocyte/primordial follicle numbers (at day 1 ) and primordial follicle numbers (day 7-200) per ovary in postnatal ovaries calculated using optical disector/fractionator stereological methods. NS indicates no significant difference from day 7 to 100 . Data presented as means \pm S.E.M. $(n=6-10)$.

Byskov \& Rasmussen (1973) estimated that $5-10 \%$ of oocytes or primordial follicles were associated with the OSE and by exiting the ovary into the periovarian space, contributed to the reduction of the pool of primordial follicles. Extrusion and release of oocytes also has been reported in the human fetal and newborn ovary (Bonilla-Musoles et al. 1975, Motta \& Makabe 1986a, Motta \& Makabe 1986b). Our studies confirm that oocytes and primordial follicles are found either in the surface epithelium or in the periovarian space from day 7 to 25 and based upon the ultrastructure, reach these locations by migration through the tunica albuginea. The number of such oocytes, estimated by stereology are

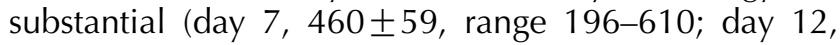
$561 \pm 85$, range $212-817$ ), representing on average $25 \%$ of the total numbers of primordial follicles counted within the ovary on these days after birth.

Oocytes in the mouse OSE were first noted on postnatal day 3 by Byskov \& Rasmussen (1973), and based upon our observations, if it is assumed that up to $25 \%$ of oocytes are lost per day by a combination of

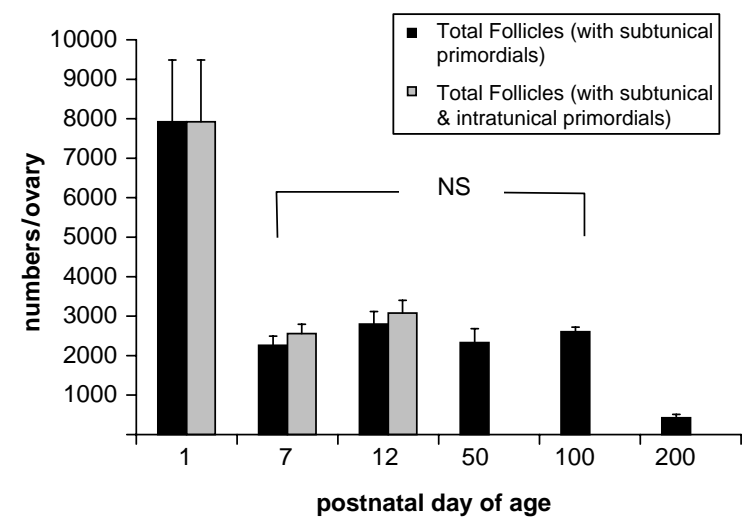

Figure 7 Total follicle or oocyte (day 1 ) numbers per ovary in postnatal ovaries calculated using optical disector/fractionator stereological methods. NS indicates no significant difference from day 7 to 200. Data presented as means \pm S.E.M. $(n=6-10)$.

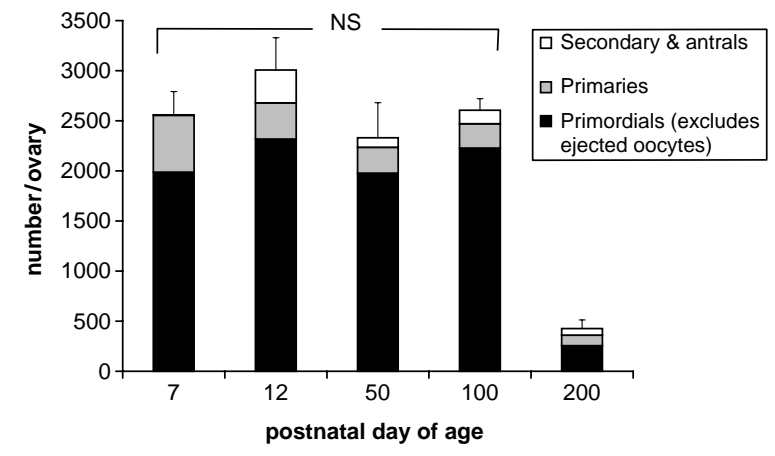

Figure 8 Numbers of indicated follicle types per ovary in postnatal ovaries calculated using optical disector/fractionator stereological methods. NS indicates no significant difference from day 7 to 200 . Data presented as means \pm s.E.M. $(n=6-8)$.

expulsion and apoptosis, it is conceivable that the 8000 oocytes on average in day 1 ovaries could decline to about 2500 as measured on day 7 . An alternative view of surface cells resembling germ cells or oocytes in the mouse ovary suggested that they represented potential germline stem cells (Johnson et al. 2004). It was proposed that these cells were a source of newly formed oocytes that replenish the otherwise declining supply of primordial follicles in the postnatal and young adult ovary. The concept that new oocytes and follicles arising from surface epithelial cells of the postnatal mouse ovary was suggested as early as 1917 by Kingery (Kingery 1917). Johnson et al. (2004) reported that surface epithelial cells were immunopositive for mouse vasa homologue (Mvh, a gene expressed exclusively in germ cells), 5-bromodeoxyuridine (an index of cell proliferation) and synaptonemal complex protein 3 (Scp3, expressed in zygotene and pachytene stages of meiosis). Based upon traditional methods of counting in paraffin sections of the ovary, Johnson et al. (2004) estimated that the 30 -day-old mouse ovary contained 63 such cells. We saw no evidence for conversion of surface epithelial cells into oocytes. Our observations suggested an alternative explanation, i.e. oocytes with or without associated stromal cells were exiting the ovary via the surface epithelium rather than arising from it. Although we did not find similar surface cells beyond day 25, our estimates of their numbers at day 7 and 12 are approximately tenfold higher than that proposed by Johnson et al. (2004). Given that we commonly observed 10-20 surface oocytes in individual 1-, 7- or $20 \mu \mathrm{m}$ sections of 7 to 15 -day-old ovaries, but less frequently at 25 days of age, the figure of 63 cells per ovary at day 30 is questionable. Expression of Mvh and Scp3 in cells proximal to the ovarian surface is not unexpected given that we have confirmed their identity as oocytes. In seeking the source of germline stem cells in juvenile and young adult ovaries (ages not specified), Johnson et al. (2004) showed examples of Mvh-labelled cells, co-labelled with $\mathrm{BrdU}$ or containing mitotic chromosomes, in 
the same locations, and suggested these were proliferating germ cells. We noted mitotic figures and many PCNA-positive cells in day 1 ovaries. In the superficial cortex of day 7 and day 12 ovaries, we found two mitotic cells and occasional PCNA-positive cells, but their identity could not be confirmed as proliferating germ cells. Such mitotic figures may represent oogonia arrested in mitosis as suggested by Wartenburg et al. (2001) and McClellan et al. (2003). Despite a thorough search for mitoses and PCNA-positive cells among primordial follicles at later ages, we found no mitotic figures and only rare examples of PCNA-labelled cells up to day 25 but none in older ovaries. Double-oocyte or closely apposed primordial follicles were seen with low frequency in 50- and 100-day-old ovaries, but this feature does not necessarily imply germ cell proliferation.

Although the mechanism by which oocytes are expelled from the early postnatal ovary remains unknown, it is likely that these oocytes are in some way selected for disposal. Extrusion of cells, independent of cell death occurs in the epithelium of the developing Drosophila wing (Gibson \& Perrimon 2005, Shen \& Dahmann 2005). Because such cells show defective cytoskeletal organization and cell adhesion, it is possible that similar changes account for the selective release of oocytes from the OSE. In all the mammalian species studied, there is an oversupply of germ cells within the late fetal ovary (Coucouvanis et al. 1993, Vaskivuo et al. 2001, Vaskivuo \& Tapanainen 2002). Depending on the species, many oocytes are eliminated by apoptosis prior to and the time of birth (Ratts et al. 1995, Reynaud \& Driancourt 2000, Shirota et al. 2003, De Felici 2004), and those that remain in the neonatal mouse ovary acquire and are surrounded by granulosa cells, establishing a pool of diplotene-arrested oocytes identified as primordial follicles (Pedersen 1969, Peters 1969). The enclosure of oocytes by granulosa cells during the first postnatal week of ovarian development exhibits temporal and spatial heterogeneity within the ovary, since larger diplotene-arrested oocytes that form primordial follicles first appear in the deep cortex and medulla (Byskov \& Nielson 2003). We noted that the superficial cortex particularly in day 1 ovaries shows smaller oocytes, many still in cell nests, together with primordial follicles. A similar sequence of primordial follicle formation suggesting a medullary-cortical gradient of maturation has been reported in the mouse ovary by Peters (1969) and McClellan et al. (2003), the rat- (Hirshfield 1992, Rajah et al. 1992, Hirshfield \& DeSanti 1995) and the sheep ovary (Sawyer et al. 2002) and appears to be a developmental pattern intrinsic to the neonatal mammalian ovary (Byskov \& Nielsen 2003). As oocytes in the ovarian medulla mature earlier than those in the superficial cortex, i.e. they are the first to reach and arrest at late diplotene of meiosis I, evidence for a developmental lag among the latter oocytes would be expected. We used GCNA immunocytochemistry as an indicator of developing oocytes, since it is expressed by germ cells in fetal and neonatal mouse ovaries, but is not detected in oocytes that become arrested at diplotene of meiosis I (Enders \& May 1994, Wang et al. 1997). Immunostaining of oocytes for GCNA confirmed the heterogeneity of oocyte maturation by showing that numerous oocytes confined to cortical locations including those in the surface epithelium and in phases of expulsion were moderately to strongly labelled. Consistent with the uncommon expulsion of oocytes beyond day 15, surface oocytes observed at later ages were rarely labelled with GCNA. Some subcortical oocytes in day 1 and day 7 ovaries were GCNA-positive, but at later ages staining of these oocytes was weak or not detected. This finding confirms that GCNA expression is first lost in medullary oocytes as they arrest at diplotene and form primordial follicles (Enders \& May 1994). A delay of meiotic maturation among oocytes located near to or in the surface epithelium may distinguish these oocytes as incapable of acquiring an appropriate number of epithelial pregranulosa cells necessary for the formation of competent primordial follicles. Factors known to be regulatory for assembly of oocytes into primordial follicles respectively include oocyte-specific transcription factors, nerve growth factor, basement membrane remodelling, and synaptonemal complex protein-1 (Soyal et al. 2000, Dissen et al. 2001, Mazaud et al. 2005, Paredes et al. 2005). Our observations show that surface-associated oocytes are disposed off by transiting the tunica albuginea followed by ejection into the periovarian space. Their subsequent fate was not determined but is likely that they degenerate and are eliminated by macrophages resident in the peritoneal cavity fluid.

Although oocyte numbers between day 1 (7924 \pm $1564)$ and day $7(1987 \pm 203)$ were significantly reduced $(P<0.001)$ by approximately $70 \%$ through a combination of expulsion and apoptosis, the mean number of primordial follicles per ovary at day 12 did not decline further $(2317 \pm 289)$ despite the simultaneous migration and expulsion of hundreds of oocytes $(561 \pm 85)$ at this time. Primordial follicle numbers per ovary remained undiminished at $50(1976 \pm 306)$ and 100 days (2227 \pm 101). The persistence of a stable population of healthy primordial follicles from day 7 to 100 was surprising given that folliculogenesis had commenced by day 7 and continuous recruitment of primordial follicles into the growth phase would have been expected to reduce the primordial follicle pool. The discordance between the lack of decay of primordial follicle numbers and those derived from them was emphasized by the total numbers of growing, healthy follicles from day 7 through to day 100 , which amounted to $17-30 \%$ of the observed primordial follicle population. Earlier studies in other strains of mice (A, CBA, CBA/A, RIII and $C B A / C a)$ 
reported a significant decline in primordial follicle numbers over the same time period. This depletion was attributed to the combination of their transition to primary follicles and to follicle death (Jones \& Krohn 1961a, Faddy et al. 1983, 1987). In four other strains, (129/Sv, DBA/2, C57BL/6 and FVB) Canning et al. (2003) reported an average $55 \%$ reduction in primordial follicles from day 4 to 42 . In contrast, primordial follicle numbers per ovary did not decline from day 30 to 120 in hybrid C3H mice (Halpin et al. 1986) and in C57BL/6 mice their numbers (shown as graphical representation) appeared to be stable from day 4 to 40 (Johnson et al. 2004).

Regardless of whether primordial follicles disappear or maintain their numbers beyond 7 days, there is a considerable body of evidence, across six strains of mice, showing that the total numbers of growing follicles per ovary (primary type and more mature) do not decline up to 120 days of age (Faddy et al. 1983, 1987, Halpin et al. 1986), a finding supported by the present study. In multiparous A and RIII strains, Jones \& Krohn (1961a) reported no significant decline in total oocytes per ovary from 98 to 371 days.

Given that the mean numbers of primordial follicles per ovary did not decline from day 7 to 100 , how is this finding explained? Several interpretations are possible: (i) the analysis produced biased counts of follicle numbers, or (ii) the rate of primordial follicle atresia and/or recruitment into growing follicles was very low, and is species- and strain-specific or (iii) new oocytes and primordial follicles were either formed in the ovary or were derived from an extraovarian source.

The first explanation is unlikely because we used unbiased stereological techniques to quantify follicles, and the 28 ovaries examined between days 7 and 100 were collected at random over several months from at least four different litters at each time point. Statistical analysis of primordial follicle number in each ovary at each day indicated no significant difference between days 7 and $100(P=0.585)$. The second possibility is difficult to evaluate as we did not quantify oocyte death or follicle atresia, and the study was not designed to estimate the rate of recruitment of primordial follicles into primary follicles. In the previous studies of the rates of follicle death and growth in developing ovaries of several strains of mice, it has been reported that the decline in primordial follicle numbers is very high in the first 4 weeks after birth but is progressively attenuated thereafter (Faddy et al. 1976, 1983, 1987, Halpin et al. 1986). The same studies have applied mathematical modelling to describe follicle dynamics and in each strain the reduction of primordial follicles per ovary as a function of age approximates an exponential decay. Because these studies did not analyse the C57BL/6 strain, it is not possible to compare directly our findings with those above. In addition, our estimates of primordial follicles per ovary as a function of age were obtained using design-based stereological (three-dimensional) methods, whereas those above, obtained with twodimensional-based methods are subject to one or more assumptions in counting as described earlier. For these reasons, we believe it would be erroneous to apply the reported data for follicle death or recruitment in other strains to our findings in an attempt to explain the constancy of healthy primordial follicles per ovary between days 7 and 100. In agreement with the earlier studies in the mouse (Pedersen 1969, Peters 1969, Faddy et al. 1976, 1983, 1987), our results show that recruitment of primordial follicles into the population of growing follicles had commenced by day 7 . At that time and at day 12, growing follicle numbers accounted for approximately $30 \%$ of total follicle numbers per ovary, yet mean primordial follicle numbers per ovary respectively at day 7 and 12 remained stable (for subtunical primordials, $1688 \pm 154$ vs $2107 \pm 272$; for sub- and intratunical primordials, $1987 \pm 203$ vs $2317 \pm$ 289 see Table 1). A similar relationship was found in adult ovaries (50 and 100 days), where mean primordial follicle numbers per ovary had not declined $(1976 \pm 306$ and $2227 \pm 101$ respectively) yet growing follicle numbers per ovary were approximately $18 \%$ of the total number counted. Our findings argue against both low rates of follicle atresia and/or recruitment as an explanation for the lack of decay of numbers of primordial follicles with increasing age. There is a possibility that the number of primordial follicles that leave the pool to either become atretic or eventually ovulate, is within the counting error up to day 100 . However, there are a number of assumptions implicit in this possibility for which there is no data for this particular strain of mouse. Furthermore, it would not explain the extensive decrease in the size of the pool of primordial follicles between days 100 and 200.

In regard to the third explanation, the persistence of primordial follicle numbers over a time period where folliculogenesis is active lends support to the notion suggested by Johnson et al. (2004, 2005a,b) that primordial follicles in the postnatal mouse ovary are replenished to maintain an adequate supply of growing follicles which are continuously depleted through atresia or ovulation. In seeking to identify the source of new oocytes within the ovary, Johnson et al. (2004) proposed that cells on the OSE were candidates for germline stem cells, capable of producing oocytes that acquired pregranulosa cells to form primordial follicles. In a further study (Johnson et al. 2005a), this hypothesis was rejected when it was found that their numbers per ovary $(63 \pm 8$ at day 30 and $6 \pm 3$ at day 40 ) were insufficient to sustain the constant supply of primordial follicles (approximately 2000 per ovary) over the same time period. Our findings are in broad agreement with this interpretation. Oogenesis leading to the formation of new oocytes has been reported in immature and adult ovaries of several primate species (Duke 1967, loannu 1967, Butler \& Juma 1970, David et al. 1974). 
The source of new germ cells was confined to germ cell nests containing dividing oogonia. In immature and adult rodent ovaries, such cell nests do not occur and no evidence of germ cell proliferation has been reported (Rudkin \& Griech 1962, Peters \& Levy 1966, Peters \& Crone 1967, Hoage \& Cameron 1976), suggesting that oogenesis in some species of prosimian primates is an isolated phenomenon.

Support for the persistence of primordial follicle numbers in the postnatal Balb/c mouse ovary is available from the studies by Cox et al. (2000). When fetal ovaries were transplanted under the kidney capsule of intact or bilaterally ovariectomized adult female mice, all grafted ovaries showed follicle maturation, yet the mean numbers of primordial follicles per ovary in the transplants did not decline from 2 to 8 weeks following transplantation.

In a further attempt to identify the source of cells capable of adding to the supply of oocytes and primordial follicles within the immature or adult ovary, Johnson et al. (2005a) have proposed that germline stem cells exist within bone marrow, the progeny of which enter the ovary via the peripheral circulation to establish new oocytecontaining primordial follicles. The notion of oocyte and follicular renewal in the postnatal mouse ovary either from within the ovary or external to it as suggested by Johnson et al. (2004, 2005a,b) has generated controversy with support for (Spradling 2004) or scepticism against the hypothesis (Albertini 2004, Bazer 2004, Gosden 2004, Telfer 2004, Greenfeld \& Flaws 2004, Bukovsky 2005, Byskov et al. 2005, Telfer et al. 2005).

Although definitive proof of the existence of the ovarian germline stem cells in the postnatal and adult mouse ovary remains to be established, our findings suggest that primordial follicle numbers remain relatively constant in association with simultaneous, active folliculogenesis. In this respect, our observations provide qualified support for an as yet unknown mechanism for follicle renewal.

\section{Acknowledgements}

This study was supported by a collaborative grant from AstraZeneca UK (J B K), and a grant from the NH\&MRC, Reg Key 241000 and 198705 (K L B and J K F). We thank Dr G C Enders (University of Kansas, Kansas City, USA) for the gift of antibody against GCNA; Dr Aidan Sudbury for statistical assistance, and Ian Boundy, Sue Connell and Richard Young for histological assistance. The authors declare that there is no conflict of interest that would prejudice the impartiality of this scientific work.

\section{References}

Albertini DF 2004 Micromanagement of the ovarian reserve - do stem cells play into the ledger? Reproduction 127 513-514.
Anand Kumar TC 1974 Oogenesis in adult prosimians. In Contribution to Primatology vol 3, Reproductive Biology of Primates pp 82-96. Eds H Balin \& SR Glaser. Amsterdam: Excerpta Medica.

Bazer FW 2004 Strong science challenges conventional wisdom: new perspectives on ovarian biology. Reproductive Biology and Endocrinology 2 28-29.

Bonilla-Musoles F, Renau J, Hernandez-Yago J \& Tirres J 1975 How do oocytes disappear? Archiv Gynaekologie 218 233-241.

Bukovsky A 2005 Can ovarian infertility be treated with bone marrowor ovary-derived germ cells?. Reproductive Biology and Endocrinology 3 36-40.

Bukovsky A, Keenan JA, Caudle MR, Wimalasena J, Upadhyaya NB \& Van Meter SE 1995 Immunohistochemical studies of the adult human ovary: possible contribution of immune and epithelial factors to folliculogenesis. American Journal of Reproduction and Immunology 33 323-340.

Bukovsky A, Caudle MR, Svetlikova M \& Upadhyaya NB 2004 Origin of germ cells and formation of new primary follicles in adult human ovaries. Reproductive Biology and Endocrinology 2 20-28.

Butler H \& Juma MB 1970 Oogenesis in an adult prosimian. Nature 226 552-553.

Byskov AG \& Rasmussen G 1973 Ultrastructural studies of the developing follicle. In The Development and Maturation of the Ovary and its Function, pp 55-62. Ed H Peters. Amsterdam: Excerpta Medica.

Byskov AG \& Nielsen M 2003 Ontogeny of the mammalian ovary. In Biology and Pathology of the Oocyte, pp 13-28. Eds AO Trounson \& RG Gosden. Cambridge: Cambridge University Press.

Byskov AG, Faddy MJ, Lemmen JG \& Andersen CY 2005 Eggs forever?. Differentiation 73 438-446.

Canning J, Takai Y \& Tilly JL 2003 Evidence for genetic modifiers of ovarian follicular endowment and development from studies of five inbred mouse strains. Endocrinology 144 9-12.

Coucouvanis EC, Sherwood SW, Carswell-Crumpton C, Spack EG \& Jones PP 1993 Evidence that the mechanism of prenatal germ cell death in the mouse is apoptosis. Experimental Cell Research 209 238-247.

Cox SL, Shaw J \& Jenkin G 2000 Follicular development in transplanted fetal and neonatal mouse ovaries is influenced by the gonadal status of the adult recipient. Fertility and Sterility 74 366-371.

David GFX, Anand Kumar TC \& Baker TG 1974 Uptake of tritiated thymidine by primordial germinal cells in the ovaries of the adult slender loris. Journal of Reproduction and Fertility 41 447-451.

De Felici M 2004 Establishment of oocyte population in the fetal ovary: primordial germ cell proliferation and oocyte programmed cell death. Reproductive Biomedicine Online 10 182-191.

Deng W \& Lin H 2001 Asymmetric germ cell division and oocyte determination during Drosophila oogenesis. International Review of Cytology 203 93-138.

Depalo R, Nappi L, Loverro G, Bettocchi S, Caruso ML, Valentini AM \& Selvaggi L 2003 Evidence of apoptosis in human primordial and primary follicles. Human Reproduction 18 2678-2682.

Dissen GA, Romero C, Hirshfield AN \& Ojeda SR 2001 Nerve growth factor is required for early follicular development in the mammalian ovary. Endocrinology 142 2078-2086.

Duke KL 1967 Ovogenetic activity of the fetal-type in the ovary of the adult slow loris, Nycticebus coucang. Folia Primatologica 7 150-154.

Enders GC \& May JJ 1994 Developmentally regulated expression of a mouse germ cell nuclear antigen examined from embryonic day 11 to adult in male and female mice. Developmental Biology 163 331-340.

Faddy MJ, Jones EC \& Edwards RG 1976 An analytical model of ovarian follicle dynamics. Journal of Experimental Zoology 197 173-186.

Faddy MJ, Gosden RG \& Edwards RG 1983 Ovarian follicle dynamics in mice: a comparative study of three inbred strains and an F1 hybrid. Journal of Endocrinology 96 23-33. 
Faddy MJ, Telfer E \& Gosden RG 1987 The kinetics of preantral follicle development in ovaries of CBA/Ca mice during the first 14 weeks of life. Cell and Tissue Kinetics 20 551-560.

Franchi LL \& MandI AM 1962 The ultrastructure of oogonia and oocytes in the foetal and neonatal rat. Proceedings of the Royal Society Series B 157 99-114.

Gibson MC \& Perrimon N 2005 Extrusion and death of DPP/BMPcompromised epithelial cells in the developing Drosophila wing. Science 307 1785-1789.

Gosden RG 2004 Germline stem cells in the postnatal ovary: is the ovary more like a testis? Human Reproduction Update 10 193-195.

Gosden RG, Laing SC, Felicio LS, Nelson JF \& Finch CE 1983 Imminent oocyte exhaustion and reduced follicular recruitment mark the transition to acyclicity in aging C57BL/6J mice. Biology of Reproduction 28 255-260.

Greenfeld C \& Flaws JA 2004 Renewed debate over postnatal oogenesis in the mammalian ovary. BioEssays 26 829-832.

Gundersen HJ 1986 Stereology of arbitrary particles. A review of unbiased number and size estimators and the presentation of some new ones, in memory of William R. Thompson. Journal of Microscopy 143 3-45.

Gundersen HJ \& Jensen EB 1987 The efficiency of systematic sampling in stereology and its prediction. Journal of Microscopy 147 229-263.

Gundersen HJ, Bagger P, Bendtsen TF, Evans SM, Korbo L, Marcussen N, Moller A, Nielsen K, Nyengaard JR \& Pakkenberg B 1988 The new stereological tools: disector, fractionator, nucleator and point sampled intercepts and their use in pathological research and diagnosis. APMIS 96 857-881.

Halpin DM, Jones A, Fink G \& Charlton HM 1986 Postnatal ovarian follicle development in hypogonadal (hpg) and normal mice and associated changes in the hypothalamic-pituitary ovarian axis. Journal of Reproduction and Fertility 77 287-296.

Hirshfield AN 1992 Heterogeneity of cell populations that contribute to the formation of primordial follicles in rats. Biology of Reproduction 47 466-472.

Hirshfield AN \& DeSanti AM 1995 Patterns of ovarian cell proliferation in rats during the embryonic period and the first three weeks postpartum. Biology of Reproduction 53 1208-1221.

Hiura M \& Fujita H 1977 Electron microscopic observations on the epithelium of the oocyte through the peritoneal epithelium in the neonatal mouse ovary. Cell and Tissue Research 182 73-79.

Hoage TR \& Cameron IL 1976 Folliculogenesis in the ovary of the mature mouse: a radioautographic study. Anatomical Record 184 699-710.

Ioannou JM 1967 Oogenesis in adult prosimians. Journal of Embryology and Experimental Morphology 17 139-145.

Johnson J, Canning J, Kaneko T, Pru JK \& Tilly JL 2004 Germline stem cells and follicular renewal in the postnatal mammalian ovary. Nature 428 145-150.

Johnson J, Bagley J, Skaznik-Wikiel M, Lee HJ, Adams GB, Niikura Y, Tschudy KS, Tilly JC, Cortes ML, Forkert R et al. 2005a Oocyte generation in adult mammalian ovaries by putative germ cells in bone marrow and peripheral blood. Cell 122 303-315.

Johnson J, Skaznik-Wikiel M, Lee H-J, Niikura Y, Tilly JC \& Tilly JL $2005 b$ Setting the record straight on data supporting postnatal oogenesis in female mammals. Cell Cycle 4 1469-1475.

Jones EC \& Krohn PL 1961 a The relationships between age, numbers of oocytes and fertility in virgin and multiparous mice. Journal of Endocrinology 21 469-495.

Jones EC \& Krohn PL 1961b The effect of hypophysectomy on age changes in the ovaries of mice. Journal of Endocrinology 21 497-509.

Kingery HM 1917 Oogenesis in the white mouse. Journal of Morphology 30 261-315.

Lin H \& Spradling AC 1995 Fusome asymmetry and oocyte determination in Drosophila. Developmental Genetics 16 6-12.
Mazaud S, Guyot R, Guigon CJ, Coudouel N, Magueresse-Battistoni BL \& Magre S 2005 Basal membrane remodeling during follicle histogenesis in the rat ovary: contribution of proteinases of the MMP and PA families. Developmental Biology 277 403-416.

McClellan KA, Gosden R \& Taketo T 2003 Continuous loss of oocytes throughout meiotic prophase in the normal mouse ovary. Developmental Biology 258 334-348.

Milhem M, Mahmud N, Lavelle D, Araki H, DeSimone J, Saunthararajah Y \& Hoffman R 2004 Modification of hematopoietic stem cell fate by 5 aza $2^{\prime}$ deoxycytidine and trichostatin A. Blood 103 4102-4110.

Miller PB, Charleston JS, Battaglia DE, Klein NA \& Soules MR 1997 An accurate, simple method for unbiased determination of primordial follicle number in the primate ovary. Biology of Reproduction $\mathbf{5 6}$ 909-915.

Morita Y \& Tilly JL 1999 Oocyte apoptosis: like sand through an hourglass. Developmental Biology 213 1-17.

Morita Y, Perez GI, Maravei DV, Tilly KI \& Tilly JL 1999 Targeted expression of $\mathrm{BCl}-2$ in mouse oocytes inhibits ovarian follicle atresia and prevents spontaneous and chemotherapy-induced oocyte apoptosis in vitro. Molecular Endocrinology 13 841-850.

Motta PM \& Makabe S 1986a Elimination of germ cells during differentiation of the human ovary: an electron microscopic study. European Journal of Obstetrics, Gynecology and Reproductive Biology 22 271-286.

Motta PM \& Makabe S $1986 b$ Germ cells in the ovarian surface during fetal development in humans. A three-dimensional microanatomical study by scanning and transmission electron microscopy. Journal of Submicroscopic Cytology 18 271-290.

Myers M, Britt KL, Wreford NGM, Ebling FJP \& Kerr JB 2004 Methods for quantifying follicular numbers within the mouse ovary. Reproduction 127 569-580.

Oktay K, Schenken RS \& Nelson JF 1995 Proliferating cell nuclear antigen marks the initiation of follicular growth in the rat. Biology of Reproduction 53 295-301.

Paredes A, Garcia-Rudaz C, Kerr B, Tapia V, Dissen GA, Costa ME, Cornea A \& Ojeda SR 2005 Loss of synaptonemal complex protein1 , a synaptonemal complex protein, contributes to the initiation of follicular assembly in the developing rat ovary. Endocrinology 146 5267-5277.

Pedersen T 1969 Follicle growth in the immature mouse ovary. Acta Endocrinologica 62 117-132.

Pepling ME \& Spradling AC 2001 Mouse ovarian germ cell cysts undergo progammed breakdown to form primordial follicles. Developmental Biology 234 339-351.

Perez GI, Robles R, Knudson CM, Flaws JA, Korsmeyer SJ \& Tilly JL 1999 Prolongation of ovarian lifespan into advanced chronological age by bax deficiency. Nature Genetics 21 200-203.

Peters H 1969 The development of the mouse ovary from birth to maturity. Acta Endocrinologica (Copenhagen) 62 98-116.

Peters H \& Levy E 1966 Cell dynamics of the ovarian cycle. Journal of Reproduction and Fertility 11 227-236.

Peters H \& Crone M 1967 DNA synthesis in oocytes of mammals. Archives d'Anatomie Microscopique et de Morphologie Expérimental 56 160-170.

Rajah R, Glaser EM \& Hirshfield AN 1992 The changing architecture of the neonatal rat ovary during histogenesis. Developmental Dynamics 194 177-192.

Ratts VS, Flaws JA, Kolp R, Sorenson CM \& Tilly JL 1995 Ablation of bcl-2 gene expression decreases the numbers of oocytes and primordial follicles established in the post-natal female mouse gonad. Endocrinology 136 3665-3668.

Reynaud K \& Driancourt MA 2000 Oocyte attrition. Molecular and Cellularl Endocrinology 163 101-108.

Richardson SJ, Senikas V \& Nelson JF 1987 Follicular depletion during the menopausal transition: evidence for accelerated loss and ultimate exhaustion. Journal of Clinical Endocrinology and Metabolism 65 1231-1237. 
Rudkin GT \& Griech HA 1962 On the persistence of oocyte nuclei from fetus to maturity in the laboratory mouse. Journal of Cell Biology 12 169-175.

Sawyer HR, Smith P, Heath DA, Juengel JL, Wakefield S \& McNatty KP 2002 Formation of ovarian follicles during fetal development in sheep. Biology of Reproduction 66 1134-1150.

Shen J \& Dahmann C 2005 Extrusion of cells with inappropriate Dpp signaling from Drosophila wing disc epithelia. Science $\mathbf{3 0 7}$ 1789-1790.

Shirota M, Soda S, Katioh C, Asai S, Sato M, Ohta R, Watanabe G, Taya K \& Shirota K 2003 Effects of reduction of the number of primordial follicles on follicular development to achieve puberty in female rats. Reproduction 125 85-94.

Sonne-Hansen K, Nielsen M \& Byskov AG 2003 Oocyte number in newborn mice after prenatal octylphenol exposure. Reproductive Toxicology 17 59-66.

Soyal SM, Amleh A \& Dean J $2000 \mathrm{FIG} \alpha$, a germ cell-specific transcription factor required for ovarian follicle formation. Development 127 4645-4654.

Spradling AC 2004 More like a man. Nature 428 133-134.

Spradling AC, Drummond-Barbosa D \& Kai T 2001 Stem cells find their niche. Nature 414 98-104.

Tan OL \& Fleming JS 2004 Proliferating cell nuclear antigen immunoreactivity in the ovarian surface epithelium of mice of varying ages and total lifetime ovulation number following ovulation. Biology of Reproduction 71 1501-1507.

Telfer EE 2004 Germline stem cells in the postnatal mammalian ovary: a phenomenon of prosimian primates and mice? Reproductive Biology and Endocrinology 2 24-25.

Telfer EE, Gosden RG, Byskov AG, Spears N, Anderson R, Braw-Tal R, Clarke H, Gougeon A, McLaughlin E, McLaren A et al. 2005 On regenerating the ovary and generating controversy. Cell 122 821-822.

Tilly JL 2003 Ovarian follicle counts - not as simple as 1, 2, 3. Reproductive Biology and Endocrinology 1 11-13.

Vaskivuo TE \& Tapanainen JS 2002 Apoptosis in the human ovary. Reproductive Biomedicine Online 6 24-35.

Vaskivuo TE, Anttonen M, Herva R, Billig H, Dorland M, Velde ER, Stenback F, Heikinheimo M \& Tapanainen JS 2001 Survival of human ovarian follicles from fetal to adult life:apoptosis, proteins, and transcription factor GATA-4. Journal of Clinical Endocrinology and Metabolism 86 3421-3429.

Vermande-van Eck GJ 1956 Neo-ovogenesis in the adult monkey. Anatomical Record 125 207-224.

Wang D, Ikeda Y, Parker KL \& Enders GC 1997 Germ cell nuclear antigen (GCNA1) expression does not require a gonadal environment or steroidogenic factor 1: examination of GCNA1 in ectopic germ cells and in Ftz -F1 null mice. Molecular Reproduction and Development 48 154-158.

Wang Y, Newton H, Spaliviero JA, Allan CM, Marshan B, Handelsman DJ \& Illingworth PJ 2005 Gonadotropin control of inhibin secretion and the relationship to follicle type and number in the $h p g$ mouse. Biology of Reproduction 73 610-618.

Wang Z \& Lin H 2004 Nanos maintains germline stem cell self-renewal by preventing differentiation. Science 303 2016-2018.

Wartenburg H, Ihmer A, Schwarz S, Miething A \& Viebahn C 2001 Mitotic arrest of female germ cells during prenatal oogenesis. A colcemid-like, non-apoptotic cell death. Anatomy and Embryology 204 421-435.

Wordinger R, Sutton J \& Brun-Zinkernagel AM 1990 Ultrastructure of oocyte migration through the mouse ovarian surface epithelium during neonatal development. Anatomical Record 227 187-198.

Wreford NG 1995 Theory and practice of stereological techniques applied to the estimation of cell number and nuclear volume in the testis. Microscopy Research and Technique 32 423-436.

Zuckerman S 1951 The number of oocytes in the mature ovary. Recent Progress Hormone Research 6 63-108.

Received 1 February 2006

First decision 9 March 2006

Revised manuscript received 27 March 2006

Accepted 20 April 2006 